\title{
Composition And Porosity Study Of Original And Restoration Materials Included In A Coastal Historical Construction
}

Morillas, Héctor; Vazquez, Patricia; Maguregui, Maite; Marcaida, Iker; Silva Oliveira, Luis Felipe.

\begin{abstract}
The materials used for the building constructions can suffer during their life numerous deterioration processes induced by different anthropogenic and natural factors. For this reason, optimal restoration works are vitally necessary for a correct Built Heritage preservation process. One of the most critical environment is the marine atmosphere (marine aerosol impact following dry and wet depositions) where the climatic conditions are very aggressive. For this reason, the new building materials that will be used for a restoration must be selected taking into account the possible deterioration sources that are present in the vicinity of the building or construction. Among marine aerosol, other factors such as biodeterioration, water infiltrations, physical stress, even pollutants than can be deposited from the surrounding environment must be taken into account. This work is focused on the analytical and physical study of the different building materials used for the restoration works carried out in 2014 in the Tower of La Galea Fortress (Getxo, Basque Country, Spain), a historical construction placed in front of the sea. The analyzed materials were the weathered sandstone (original sandstone) and the one used to replace it (restoration sandstone), as well as restoration joint and rendering mortars. The results presented in this work offered a global idea of the correct material selection, taking into account the different factors that can affect the integrity of the whole building in the future. In order to test the durability of these materials against the surrounding environment, different analyses were carried out. On the one hand, X-ray Diffraction (XRD), Raman spectroscopy and Wavelength Dispersive X-ray fluorescence (WD-XRF) were used for chemical characterization of the materials. On the other hand, Mercury Intrusion Porosimetry (MIP) was used to understand the porous system and the thermal behavior was studied using Infrared Thermography (IRT). Finally, the thermal fatigue test was carried out to determine if temperature cycles could have impact in the structural integrity and aesthetic appearance (i.e. color changes) of these materials during time.
\end{abstract}




\section{Keywords}

Infrared Thermography; Marine Aerosol; Raman Spectroscopy; Restoration; Sandstone; X-Ray Diffraction 